\title{
Analysis of stability of railway embankment including horizontal forces in light of Eurocode
}

\author{
Karol Brzeziński ${ }^{1, *}$, Tomasz Rybicki ${ }^{1}$, and Kazimierz Józefiak ${ }^{1}$ \\ ${ }^{1}$ Warsaw University of Technology, Faculty of Civil Engineering, 00637 Kaczyńskiego 16, Warsaw, \\ Poland
}

\begin{abstract}
The subject of this paper is analysis of the influence of horizontal forces estimated on the basis of Eurocode on the stability of an exemplary railway embankment located in the horizontal curve. The work begins with an overview of the methods for determining the earthworks stability. The methods are presented along with a reference to the recommendations contained in Eurocode 7. On the basis of the Eurocode, the loads acting on the analyzed embankment are presented together. In addition to the standard vertical interactions (from the rolling stock, the weight of the track structure and ground), the calculations also take into account horizontal forces caused by: wind forces on rolling stock, centrifugal forces and nosing force of the rolling stock as well as thermal stresses in the rails. Next, there are 15 load combinations calculated according to the Eurocode guidelines. At the end of the work the values of safety factors of the embankment obtained by shear strength reduction method are presented. The obtained results show a significant influence of horizontal forces calculated on the basis of the Eurocode on the stability of the railway embankment analyzed in the work.
\end{abstract}

\section{Introduction}

Standard railway embankment stability calculations take into account only the vertical impact of rolling stock, the weight of railway track and the ground. This approach is justified, since the PN-EN 1991-2: 2007 standard [1] for railway earthworks specifies only the vertical loads. Also the technical specifications for interoperability (TSI) [2] for railway earthworks, indicate only the need to take into account vertical loads. However, if the railroad track is curved, the centrifugal force affects the embankment when the train is passing. The wind force acting transversely on the rolling stock and the nosing force are also transferred to the embankment. Also, thermal forces in the curved rails generate lateral pressure of the track on the ballast, and thus on the embankment. The above horizontal impacts can have a significant impact on the railway embankment stability. The aim of the work was to analyze the influence of these impacts on the stability of an exemplary railway embankment located in the horizontal curve. It was estimated on the basis of Eurocodes [1, $3,4]$. On the basis of this analysis, the practical significance of taking into account the

\footnotetext{
* Corresponding author: k.brzezinski@il.pw.edu.pl
} 
influence of horizontal forces in the slope stability determination procedures was assessed. Only permanent situations relating to normal conditions of use are included in the calculation. The transient situations have been omitted, relating, for example, to the construction or reconstruction of an object, as well as exceptional situations, e.g. derailment.

\section{Methodology}

\subsection{Slope stability analysis}

Methods for assessing the overall stability of earthworks can be divided into the following $[5,6]$ :

- limit equilibrium analysis,

- limit stress analysis,

- shear strength reduction analysis,

- empirical methods.

According to Eurocode 7 [4], the first method is considered to be the primary one, and the second and third methods are alternative, while empirical methods are reflected in the rules for the use of comparable experiences.

In this work the method of shear strength reduction (SSR) was used. In this method, the stability of the earth structure is analyzed based on the state of stress and strain of the soil material. During the calculation, the shear strength of the soil is reduced by reducing the strength parameters of the soil. Normally, the tangent value of the internal friction angle and cohesion are reduced proportionally by dividing them by an increasing factor until the stability is lost (Eq. 1 and 2).

$$
\begin{aligned}
\operatorname{tg} \varphi & =\operatorname{tg} \varphi F S_{i} \\
c_{i} & =c / F S_{i}
\end{aligned}
$$

where : $\varphi$ - internal friction angle, $\varphi$ - reduced internal friction angle, $c$ - cohesion, $c_{i}-$ reduced cohesion, $F S_{i}$ - coefficient of soil strength parameter reduction. The highest achieved coefficient is also an indicator of slope stability.

$$
F S=F S_{\max }
$$

The ADONIS program based on the finite element method (FEM) [7] was used to determine the state of stress and strain in the soil medium. A two-dimensional model was adopted, where the soil structure is represented by a characteristic cross-section in plane strain state.

Different constitutive models of the soil material can be used in the calculations. The simplest of them is the linear-elastic model that allows to determine the strain and stress state without taking into account changes in soil the properties during the loading [8]. More complex models are non-linear models that take into account changes in soil properties during loading, e.g. plasticity. This group of models includes Coulomb-Mohr, DruckerPrager, Cam-Clay [6]. The analysis only focused on the GEO ultimate limit state of resistance. It means the destruction or excessive deformation of the ground when the strength of the ground or rock is decisive for ensuring the load capacity. This is the basic limit state of bearing capacity according to Eurocode 7 [5]. 
When checking the limit state of the bearing capacity (GEO), it must be proved that the following condition has been met:

$$
E_{d} \leq R_{d}
$$

where : $E_{d}$ - design value of effects of actions, $R_{d}$-design resistance.

The above condition can be represented as follows:

$$
S F_{d}=R_{d} / E_{d} \geq 1
$$

where : $S F_{d}$ - safety factor.

It should be noted that the safety factor of at least 1 is sufficient, because the safety reserve is provided by the coefficients that modify the design values of the effects of actions and the design value of the ground resistance. In this work, partial factors for geotechnical parameters (angle of internal friction and cohesion) $\gamma_{M}=1.25$.

\subsection{Description of the designed earth structure}

The subject of the analysis is a geotechnical structure in the form of a high embankment situated in a curve with a small radius. On the embankment there is an unelectrified track of a first-class railway line. The normal cross-section is shown in Figure 1.

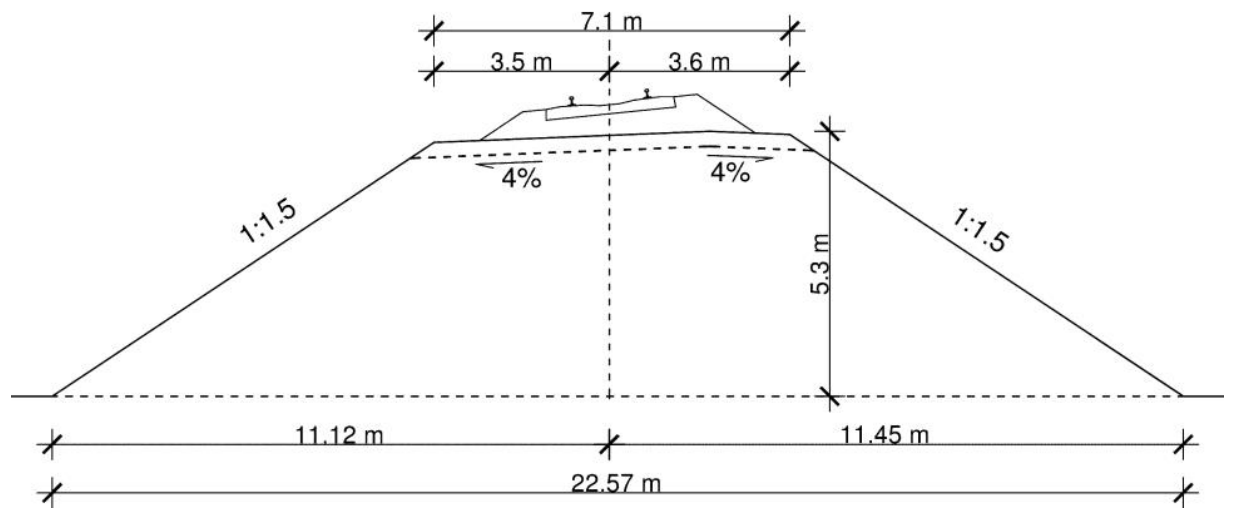

Fig. 1. The normal cross-section of the embankment.

The parameters of the designed railway track on the embankment are presented below.

- radius of horizontal curve - $\mathrm{R}=460 \mathrm{~m}$

- superelevation - $\mathrm{D}=150 \mathrm{~mm}$

- maximum speed - V=100 km/h

- maximum permissible loads [9] - D4 (22.5 t/axis, 8.,0 t/m)

It is planned to place the class 1 railway superstructure in the construction variant $1.1[10]$, consisting of the following elements:

- rails: $60 \mathrm{E} 1$

- rail fastening: SB-4

- ties: PS-94 in the spacing $0.60 \mathrm{~m}$

- ballast: crushed stone, depth $-0.35 \mathrm{~m}$.

The sub-ballast (blanket layer) is designed of coarse aggregate with a grain size of 0 $31.5 \mathrm{~mm}$. The embankment material is coarse sand. The base of the embankment is sandy clay. The adopted material parameters are summarized in Table $1[11,12]$. 
Table 1. Material parameters

\begin{tabular}{|c|c|c|c|c|c|}
\hline Material & Bulk density & $\begin{array}{c}\text { Friction } \\
\text { angle }\end{array}$ & Cohesion & $\begin{array}{c}\text { Young's } \\
\text { modulus }\end{array}$ & $\begin{array}{c}\text { Poisson's } \\
\text { ratio }\end{array}$ \\
\hline $\begin{array}{c}\text { Coarse } \\
\text { aggregate }\end{array}$ & $1.85 \mathrm{~g} / \mathrm{cm}^{3}$ & $45.0^{\circ}$ & $1.0 \mathrm{kPa}$ & $200 \mathrm{MPa}$ & 0.20 \\
\hline Coarse sand & $1.80 \mathrm{~g} / \mathrm{cm}^{3}$ & $40.0^{\circ}$ & $2.0 \mathrm{kPa}$ & $100 \mathrm{MPa}$ & 0.25 \\
\hline Sandy clay & $2.20 \mathrm{~g} / \mathrm{cm}^{3}$ & $18.3^{\circ}$ & $31.5 \mathrm{kPa}$ & $21.1 \mathrm{MPa}$ & 0.29 \\
\hline
\end{tabular}

\subsection{Adopted loading model}

According to the regulation [14] and the standard [1], a vertical load model LM 71 with the load classification coefficient $(\alpha=1.21)$ was used to check the stability of the designed structure. The concentrated loads were distributed evenly linearly along the track axis. In addition to the analysis, the load model "train without cargo" was adopted in accordance with clause 6.3 .4 of the standard [1]. For the above vertical forces, the eccentricity (relative to the track axis) was calculated taking into account the maximum effect of lateral displacement of vertical loads and the influence of cant.

Based on the adopted load models, due to the curvature of the track axis, horizontal centrifugal forces have been considered on the structure. These forces were calculated for the maximum superelevation and cant deficiency (assuming full implementation of [2] to Polish regulations). The side impact force was also taken into account. For horizontal forces an eccentricity was calculated relative to the level of the track, taking into account the influence of cant. No coefficient or dynamic surplus was applied to the above characteristic traffic loads.

The design values of the effects of actions were determined using the factors $\psi$ presented in Table 2 .

Table 2. Factors for combination value of variable loads $\psi$ ) [16]

\begin{tabular}{|c|c|}
\hline Load & $\boldsymbol{\Psi}$ \\
\hline model LM 71 & 0.80 \\
\hline „train without cargo" model & 1.00 \\
\hline nosing force & 1.00 \\
\hline wind & 0.75 \\
\hline temperature & 0.60 \\
\hline
\end{tabular}

In order to simplify calculations, transverse slopes of the track were omitted while creating the embankment calculation model. All loads were applied to the horizontal reference surface located and $0.70 \mathrm{~m}$ below the level of the track.

Depending on how large the eccentricity generated horizontal loads, different substitution distributions of stresses applied to the horizontal reference surface were assumed. An exemplary distribution is shown in Figure 2. 


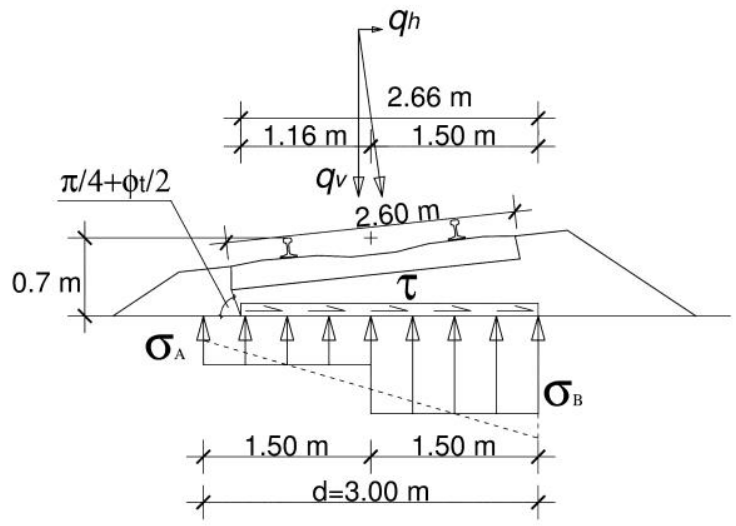

Fig. 2. The transverse distribution of variable interactions on the reference surface.

In the above case, the vertical impacts transmitted to the embankment by the rolling stock were spread over the reference surface at a width of $3 \mathrm{~m}$, however, due to the influence of horizontal forces, to maintain global equilibrium equations, normal stresses were varied on two $1.5 \mathrm{~m}$ wide bands.

Horizontal impacts were distributed evenly on the reference surface. The range of tangential stress on the left side of the track was limited in accordance with [13], while on the right side of the track it was limited by the range of normal stresses.

Fifteen different load combinations were included in the calculations.

The combinations that do not take into account horizontal forces were assumed as the reference:

- the load combination (0), which only takes into account the vertical load from the weight of the railway superstructure

- the load combinations $(1,2)$, which, in addition to the weight of the superstructure, also considered vertical forces from railway traffic load unevenly distributed due to eccentricity due to track cant,

- the load combinations $(3,4)$, which in addition to the weight of the superstructure, also consider vertical forces from the railway traffic load distributed (without the eccentricity) evenly over the width of $3 \mathrm{~m}$.

Due to the simultaneous occurrence of wind actions with the impact of railway traffic, according to [3], the following combinations were introduced:

- the load combinations (from 5 to 10 ), in which the vertical and horizontal impact of railway traffic constitute the main impact together with the additional impact of wind,

- the load combinations $(11,12)$, in which the wind impact is the main impact together with - the accompanying vertical and horizontal impact of railway traffic,

- the load combinations $(13,14)$, in which the wind impact is the main impact together with the accompanying vertical and horizontal impact of the rail traffic load model "train without cargo".

In all load combinations taking into account horizontal forces (from 5 to 14) thermal effects were also taken into account additionally.

Due to the fact that some of the load models from the Eurocode are not evenly distributed along the track, and the calculations are to be carried out in a two-dimensional model assuming a plane strain state, two extreme groups of computational cases were analyzed: omitting local increases in these loads (models with odd numbers) or considering them to be effective over the entire length of the embankment (models with even numbers). 


\section{Results and discussion}

The results of calculations in the form of embankment stability factors obtained for individual combinations of loads are presented in Table 3. The exemplary displacement contour plots are presented in Figures 3 and 4. On their basis one can infer the slip surface shape.

Table 3. Setting Word's margins.

\begin{tabular}{|c|c|}
\hline No & Safety Factor \\
\hline 0 & 1.309 \\
\hline 1 & 1.226 \\
\hline 2 & 1.141 \\
\hline 3 & 1.285 \\
\hline 4 & 1.184 \\
\hline 5 & 1.273 \\
\hline 6 & 1.133 \\
\hline 7 & 1.219 \\
\hline 8 & 1.023 \\
\hline 9 & 1.164 \\
\hline 10 & 0.930 \\
\hline 11 & 1.090 \\
\hline 12 & 0.668 \\
\hline 13 & 1.180 \\
\hline 14 & 0.188 \\
\hline
\end{tabular}

In the most cases, obtained safety factors were equal 1 or more, which means a safe situation for the structure. However, the impact of horizontal loads is noticeable, as the safety factors for combinations containing horizontal loads are lower than for the base combination taking into account only vertical loads. On the other hand, it should be noted that in the case of load combinations from 11 to 14, the eccentricity of forces transmitted to the track by the rolling stock exceeds the distance between the rails, which would in fact lead to the vehicle rollover. Such a large eccentricity is caused by the reduction of the vertical traffic load with simultaneous large values of horizontal impacts. Apart from the above rollover effect, one can still imagine direct application of tensile forces to the structure of bridges (for which the load models and load combination rules in the Eurocode were created), which is impossible in the case of earthworks. Therefore, the use of these combinations in design practice is not recommended for earthworks. 


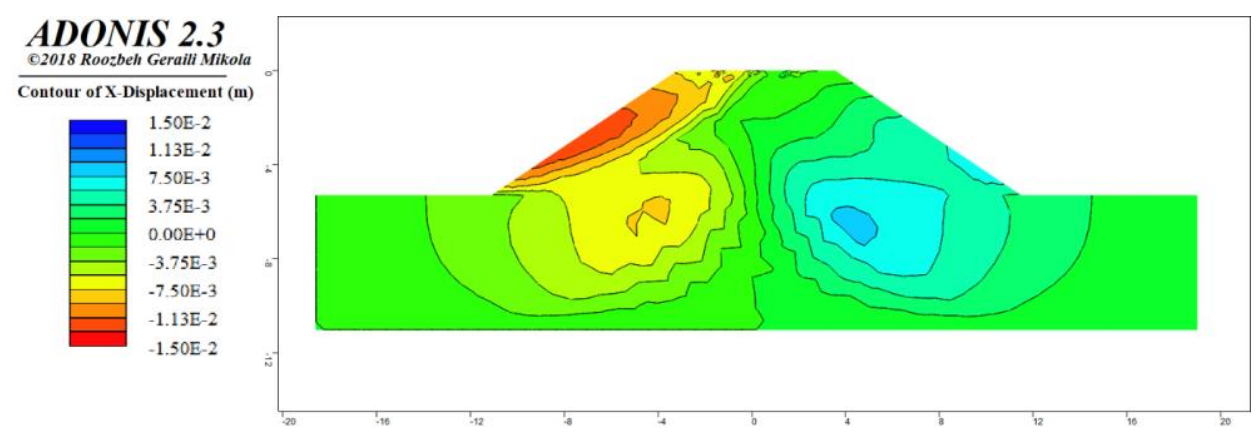

Fig. 3. Contour plot of horizontal displacements obtained by SSR method for load combination 1.

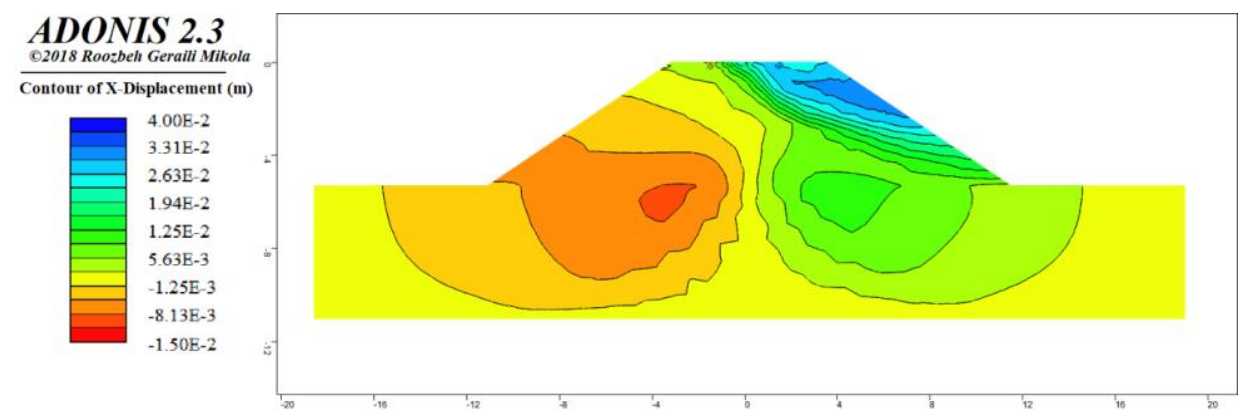

Fig. 4. Contour plot of horizontal displacements obtained by SSR method for load combination 6.

\section{Conclusions}

On the basis of the analyzes carried out, conclusions can be drawn regarding the influence of the analyzed horizontal impacts on slope stability. Vertical traffic loads in relation to the total weight of the embankment, especially high, are relatively small. As the depth increases, the proportion of stresses from the traffic loads decreases. However, as can be concluded from the comparison of results obtained for combinations of 0 and 1, 2, 3 and 4 loads, vertical traffic loads have a significant impact on reducing the values of safety factors obtained.

Centrifugal forces have a large share in the sum of all horizontal forces - in load combinations for the LM 71 load model, they constitute from $45 \%$ to $75 \%$ of these forces. Thus, centrifugal forces have a significant influence in reducing the safety factor of the embankment due to the horizontal forces.

The wind load on the rolling stock on the embankment reaches significant values. This is related to the unfavorable ratio of the transverse dimensions of the rolling stock resulting in a significant value of the wind strength coefficient (aerodynamic resistance), as well as a small distance from the edge of the embankment resulting in the adoption of a large value of the terrain factor. However, wind forces have a relatively small share in the sum of all horizontal forces - in load combinations for the LM 71 load model, they constitute from $6 \%$ to $23 \%$ of these forces. On the other hand it should be noted that the field conditions adopted at work are not the most unfavorable ones. 
Thermal forces have the least impact (in relation to other horizontal forces) on the stability of the railway embankment analyzed in the work. However, in the limit state, the pressure from these forces could have a decisive influence on the destruction of the embankment. The influence of thermal forces on the excitation of the embankment limit state could be greater in the case of a smaller curve radius.

In order to analyze the problem more accurately, it would be necessary to perform stability calculations for a larger number of embankments differing in height, ground and water conditions, location of the axis of the track relative to the edge of the embankment (other dimensions of sleepers, ballast heaps, track benches, other cant), terrain type due to on the impact of wind etc.

\section{References}

1. PN-EN 1991-2:2007 - Eurocode 1: Actions on structures - Part 2: Traffic loads on bridges (in Polish)

2. Commission Regulation (EU) No 1299/2014 of 18 November 2014 on the technical specifications for interoperability relating to the 'infrastructure' subsystem of the rail system in the European Union Text with EEA relevance (Dz. U. L 356 z 12.12.2014) (in Polish)

3. PN-EN 1990:2008 - Eurocode: Basis of structural design (in Polish)

4. PN-EN 1997-1:2008 - Eurocode 7: Geotechnical design - Part 1: General rules (in Polish)

5. M. Das, Braja, Geotechnical engineering handbook (J. Ross Publishing, 2010)

6. A. Stopkowicz, M. Cała., Mod. Build. Eng. 3, 62-65, (2007) (in Polish)

7. M. R. Geraili, GeoOttawa (2017), 553, (2017)

8. C. Kraśkiewicz, R. Michalczyk, K. Brzeziński, M. Płudowska, Proc. Eng. 111, 462 (2015)

9. PN-EN 15528:2015-12 - Railway applications. Line categories for managing the interface between load limits of vehicles and infrastructure (in Polish)

10. Id-1 (D-1) - Technical conditions for maintaining the track structure on railway lines, PKP PLK S.A., Warsaw (2005) (in Polish)

11. Z. Wiłun, Outline of geotechnics (in Polish), (WKŁ, Warsaw 2000)

12. PN-81/B-03020 - Soils - Direct foundation of structures - Static calculations and design (in Polish)

13. PN-S-10030:1985 - Bridges - Loads (in Polish)

14. Regulation of the Minister of Transport and Maritime Economy of September 10, 1998 on technical conditions to be met by railway structures and their location (Dz. U. $\mathrm{z}$ 1998 r. Nr 151, poz. 987, z późn. zm.) (in Polish) 